\title{
Diabetes outbreak during COVID19 lock- down in a prediabetic patient with cystic fibrosis long treated with glargine
}

\author{
Francesco Maria Rosanio ${ }^{1 \dagger}$, Enza Mozzillo ${ }^{1 * \dagger} \mathbb{D}$, Chiara Cimbalo², Alberto Casertano', Angela Sepe ${ }^{2}$, Valeria Raia²,
} Adriana Franzese ${ }^{1}$ and Antonella Tosco ${ }^{2}$

\begin{abstract}
Background: Cystic Fibrosis Related Diabetes (CFRD) is a frequent comorbidity of patients with Cystic Fibrosis (CF). A worsening of clinical conditions appears before CFRD. It has been demonstrated a decline in pulmonary function and nutritional status also in patients with prediabetes. Few trials show that insulin may be beneficial in prediabetic CF patients, to date guidelines do not recommend for this condition.

Case presentation: We report a case of a patient treated with insulin glargine at 13 years, due to glycemic intolerance, and with Lumacaftor/lvacaftor at 15 years. A reduction of pulmonary exacerbations was observed after glargine therapy, also confirmed after the starting of Lumacaftor/ Ivacaftor in this patient. Pulmonary function improved only after the first year of glargine therapy, then a deterioration appeared due to the natural history of CF lung damage. During the COVID-19 lockdown, poor adherence to care contributed to diabetes mellitus onset needing high insulin requirements. After two weeks the patient returned to prediabetic condition and his previous dose of glargine.

Conclusions: our case highlights firstly that insulin glargine has contributed to preserve him from further clinical worsening due to prediabetes in the years before pandemic, secondly the negative impact of COVID-19 lockdown on the clinical course of a chronic disease as CF.
\end{abstract}

Keywords: Cystic fibrosis related diabetes, Prediabetes, Glucose derangements, Insulin, Glargine, Oral glucose tolerance test, COVID19, Lockdown

\section{Background}

Cystic fibrosis (CF) is the most common autosomal recessive disease in Caucasians, with a worldwide prevalence of 1 in 2500 live births [1]. Patients with CF may develop numerous disease-related comorbidities, the most common is diabetes mellitus which manifests after a progressive reduction in glucose tolerance [2]. The

\footnotetext{
* Correspondence: mozzilloenza@gmail.com

${ }^{\dagger}$ Francesco Maria Rosanio and Enza Mozzillo contributed equally to this work. ${ }^{1}$ Regional Center of Pediatric Diabetes, Department of Translational Medical Science, Section of Pediatrics, Federico II University of Naples, Naples, Italy Full list of author information is available at the end of the article
}

pathophysiology of CF-related diabetes (CFRD) is extremely complex. As in type 1 diabetes mellitus (T1DM), progressive loss of pancreatic islet cells occurs in CFRD; however, unlike T1DM, beta cell autoimmunity markers are negative and the onset of diabetic ketoacidosis (DKA) is extremely rare since there is a minimal insulin production. As in type 2 diabetes mellitus (T2DM), insulin resistance occurs, linked to frequent infective pulmonary exacerbations or use of glucocorticoid agents. Glucose homeostasis is further disrupted by the requirement for high caloric intake, gut abnormalities and liver disease resulting in progressive insulin deficiency [3]. 
Since CFRD is often clinically silent, and glycosylated haemoglobin (HbA1c) is not considered a diagnostic tool, due to its small reliability with the glucose impairment, routine screening by oral glucose tolerance test (OGTT) is recommended. The OGTT is the only accepted screening test, starting from ten years of life and performed in stable baseline health conditions. Some authors suggested to extend OGTT test as screening of early glucose derangements under 10 years of age also $[4,5]$. According to the American Diabetes Association (ADA) [6] and the ISPAD guidelines [7], diagnosis of diabetes can be made, during acute illnesses, when fasting plasma glucose (FPG) levels $\geq 126 \mathrm{mg} / \mathrm{dL}$ ( $\geq 7.0$ $\mathrm{mmol} / \mathrm{L})$ or plasma glucose $\geq 200 \mathrm{mg} / \mathrm{dL}(\geq 11.1 \mathrm{mmol} /$ L) persist for more than $48 \mathrm{~h}$. During a period of stable baseline health, if FPG level is $\geq 126 \mathrm{mg} / \mathrm{dL}(\geq 7.0 \mathrm{mmol} /$ $\mathrm{L})$ or $\geq 200 \mathrm{mg} / \mathrm{dL}(\geq 11.1 \mathrm{mmol} / \mathrm{L})$ at time (T) 120 of the OGTT; or if random blood glucose is $\geq 200 \mathrm{mg} / \mathrm{dL}$ ( $\geq$ $11.1 \mathrm{mmol} / \mathrm{L}$ ) on 2 or more occasions with symptoms, diagnosis of CFRD-fasting hyperglycemia plus (CFRD$\mathrm{FH}+$ ) and less (CFRD-FH-) can be respectively performed. Normal glucose tolerance (NGT) is defined by fasting blood glucose $<100 \mathrm{mg} / \mathrm{dL}(<5.5 \mathrm{mmol} / \mathrm{L})$ or $<$ $140 \mathrm{mg} / \mathrm{dL}(<7.7 \mathrm{mmol} / \mathrm{L})$ at T120 of OGTT. The OGTT may reveal other prediabetic glucose alterations: impaired glucose tolerance (IGT), if blood glucose $\geq 140$ $\mathrm{mg} / \mathrm{dL} \quad(\geq 7.7 \mathrm{mmol} / \mathrm{l})$ and $<200 \mathrm{mg} / \mathrm{dL} \quad(<11.1 \mathrm{mmol} / \mathrm{l})$ at T120 and Indeterminate Glucose Tolerance (INDET) in NGT patients with one or more glucose values $\geq 200$ $\mathrm{mg} / \mathrm{dL}(\geq 11.1 \mathrm{mmol} / \mathrm{L})$ at T30, T60 and/or T90 during OGTT [7]. Children with IGT or INDET compared to those with NGT show increased risk to develop CFRD $[8,9]$. CFRD can also occur early in childhood [10] with increased prevalence as patients get older [2]. An insidious decline in clinical status of patients with CF showing early glucose alterations has been described in the years before the diagnosis of CFRD [11-14]. In children the decline in pulmonary function and nutritional parameters, correlated with insulin insufficiency, appear long before glucose levels are high enough to diagnose CFRD $[15,16]$ as in adults where prediabetes has a negative impact on the number of respiratory exacerbations, on the lung function and on the nutritional status even 2-4 years before CFRD diagnosis [17-19]. In IGT patients the drop in forced expiratory rate in the first second (FEV1) after four years of follow-up is higher as compared to NGT [11]. Insulin secretion in IGT is significantly lower than that of NGT patients, and the FEV1 positively correlates with beta cell function, as assessed by insulin resistance index HOMA\% B [20]. The condition of insulin-deficiency determines an increase in protein catabolism [21]. Moreover, a more active inflammatory state (higher fibrinogen level) has been demonstrated in patients with IGT [20], therefore this may contribute to augment the pulmonary exacerbations. According to ISPAD guidelines [7] insulin therapy is the only recommended medical treatment for CFRD and evidence that insulin treatment may have an advantage on clinical outcomes of CF children showing early glucose derangements is scarce. In our previous report we showed that insulin treatment could represent an important strategy to improve lung function and BMI zscore, and to reduce pulmonary exacerbations in patients with CF showing prediabetic glucose alterations $[14,22]$. We present a case of an adolescent with CFRD onset during the COVID-19 pandemic lockdown, but already treated with glargine basal insulin due to a prediabetic condition diagnosed four years earlier.

\section{Case presentation}

$\mathrm{S}$. is a 17 year old white male with CF (genotype delta F508 homozygous) associated to pancreatic insufficiency diagnosed at one month of life in therapy with lumacaftor/ivacaftor since he was 14 years. He had his first OGTT screening at 10 years of age. When he was 13year old, diagnosis of IGT was made according to OGTT, 2-h glucose value was $142 \mathrm{mg} / \mathrm{dL}(7.9 \mathrm{mmol} / \mathrm{L})$. Laboratory investigations showed that diabetes autoantibodies were negative while there had been an increase of $\mathrm{HbA1C}$ plasma value ranged from 5.7 to $6.5 \%$ (38 to $47.6 \mathrm{mmol} / \mathrm{L}$ ). Since the patient in the last year had shown an impairment of the clinical conditions including decrease in percent predicted FEV1 (ppFEV1\%) and BMI z-score, and increase in the number of lung infections, we decided to start off label use of insulin. After signing informed consent, basal insulin therapy with glargine at $0.1 \mathrm{units} / \mathrm{Kg} /$ day was prescribed and administered. After twelve months of glargine therapy, pulmonary exacerbations requiring intravenous antibiotic therapy were reduced from 4 to 2 exacerbations per year with a stabilization of FEV1\% and BMI z-score. At the age of 15 years he started modulators therapy with the association of Lumacaftor/Ivacaftor [23]. For 2 years he had no need for intravenous antibiotic therapy with stable FEV1\% and a slight increase of BMI z-score. At the age of 17 years, during COVID-19 pandemic lockdown, S. presented recurrent headache, abdominal pain and weight loss of $1.5 \mathrm{~kg}$ (BMI z-score-2.4), polyuria and polydipsia. He was admitted to our Cystic Fibrosis Center in the suspicion of a pulmonary exacerbation. Physical examination showed dehydration and dystrophy, while chest auscultation showed crepitus and rales in the mid-apical lung fields bilaterally and clubbing, with oxygen saturation $96-97 \%$ in ambient air. The sudden loss of his father one month earlier, due to an acute myocardial infarction, was reported by the mother, who also referred a reduced adherence to all care of the patient, an excessive consumption of high- 
calorie foods associated with physical inactivity due to the lockdown, and a state of agitation. Laboratory investigations revealed glycemia $380 \mathrm{mg} / \mathrm{dL}(21.1 \mathrm{mmol} / \mathrm{L})$, no chetoacidosis ( $\mathrm{pH} 7.35$, bicarbonate $23 \mathrm{mEq} / \mathrm{L}$, betahydroxybutyrate $1 \mathrm{mmol} / \mathrm{L}), \quad$ C-peptide $0.2 \mathrm{ng} / \mathrm{mL}$, HbA1c $12.1 \%(108.5 \mathrm{mmol} / \mathrm{L})$. The protein $\mathrm{C}$ reactive was $32.9 \mathrm{mg} / \mathrm{l}$ (normal range $<5$ ) with blood count within normal range. Type 1 diabetes autoantibodies were retested and resulted negative. Nasopharyngeal swab and serological tests for SARS-CoV-2 were negative. Intravenous antibiotic therapy with amikacin and meropenem was started with normalization of inflammation markers. His insulin dose before lockdown was 5 units/day ( 0.10 units $/ \mathrm{kg} /$ day). Insulin lispro was added to meals (with a carbohydrate ratio of 1 unit per $30 \mathrm{~g}$ carbohydrates, a sensitivity of 1 unit per $90 \mathrm{mg} / \mathrm{dL}$ ) in addition to the increasing of insulin glargine for a total insulin requirement of 17 units/day ( 0.35 units $/ \mathrm{kg} /$ day). A glucose monitoring system was started using an intermittent scanning sensor. After about 2 weeks, there was an improvement in glycemic control, ultrafast insulin was discontinued and S. returned to a pre-lockdown insulin dose. During hospitalization the main microvascular complications (i.e., microalbuminuria and retinopathy) were screened and resulted negative. At discharge, a new nasopharyngeal swab test for SARS-CoV-2 was repeated and resulted negative. To date, the insulin dose of $\mathrm{S}$. has remained 0.1 units $/ \mathrm{kg} /$ day (insulin glargine only), his BMI $\mathrm{z}$-score has improved with a slight increase in FEV1\%. Patient data before and after glargine and modulators therapy are presented in Table 1.

\section{Discussion and conclusions}

Diabetes has a major negative impact on the clinical outcome of patients with CF. Although to a lesser extent, this has also been demonstrated in patients who show prediabetic alterations and who are at a high risk of developing diabetes. Identification of prediabetic $\mathrm{CF}$ patients may provide for improving or delaying clinical impairment [14]. According to ISPAD guidelines [7], there are no consistent recommendations to determine whether insulin treatment should also be used for all INDET and IGT patients, as well as in the previous ISPAD 2014 guidelines [24]. Through its promoting action on protein synthesis, insulin is known to improve nutritional and metabolic outcomes, and consequently lung function, even in patients with mild glycemic impairment. The IGT status indicates an insulin deficiency which leads to protein catabolism with a consequent negative impact on respiratory function by reducing diaphragm and intercostal muscle mass and strength. Early treatment with insulin could prevent this excessive catabolism [25]. Although there was no clear indication to start insulin therapy in S., who resulted IGT at the OGTT carried out in 2016, we decided to treat him with insulin, considering the severity of his underlying condition. Before starting insulin therapy S. showed frequent pulmonary flare-ups and difficulty in gaining and maintaining weight which required numerous hospitalizations for intravenous antibiotic therapy. After the initiation of insulin therapy we reported an important reduction of pulmonary exacerbations, probably explained by positive effect of glargine on anabolic metabolism and respiratory muscles strength. This positive trend was also confirmed after the starting of modulator therapy (Lumacaftor/ Ivacaftor). Regarding pulmonary function, S. showed an encouraging increasing of FEV1 only in the first year of insulin therapy, then an unrelenting deterioration appeared due to the natural history of CF lung damage, despite the Lumacaftor/Ivacaftor therapy. Respect to the nutritional status a noticeable impairment in BMI $\mathrm{z}$ score occurred when overt diabetes appeared. The latter was probably secondary to the poor adherence to therapy, the loss of the father, and the physical inactivity due to the COVID-19 lockdown. During lockdown S lifestyle dramatically changed determining absence from school

Table 1 Patient data before and after Glargine therapy

\begin{tabular}{lllllll}
\hline & $\begin{array}{l}\text { Age } \\
\text { (years) }\end{array}$ & $\begin{array}{l}\text { Lumacaftor } \\
\text { Ivacaftor }\end{array}$ & $\begin{array}{l}\text { BMI } \\
\text { Z- } \\
\text { score }\end{array}$ & $\begin{array}{l}\text { FEV1 } \\
\text { (\%) }\end{array}$ & $\begin{array}{l}\text { Annual number of } \\
\text { pulmonary exacerbations }\end{array}$ & $\begin{array}{l}\text { Annual number of pulmonary exacerbations } \\
\text { treated by intravenous antibiotics }\end{array}$ \\
\hline $\begin{array}{l}\mathbf{2 0 1 6} \text { (before Glargine } \\
\text { therapy) }\end{array}$ & 13.1 & NO & -1.58 & $90.4 \%$ & 7 & 4 \\
$\begin{array}{l}\mathbf{2} 017 \text { (1 year of } \\
\text { Glargine therapy) }\end{array}$ & 14.5 & NO & -1.54 & $91 \%$ & 4 & 2 \\
$\begin{array}{l}\mathbf{2} 1 \mathbf{1} \text { (2 years of } \\
\text { Glargine therapy) }\end{array}$ & 15.7 & YES & -1.47 & $75 \%$ & 2 & 0 \\
$\begin{array}{l}\mathbf{2} 19 \text { (3 years of } \\
\text { Glargine therapy) }\end{array}$ & 16.3 & YES & -1.78 & $74 \%$ & 3 & 0 \\
$\begin{array}{l}\mathbf{2 0 2 0} \text { (COVID-19 } \\
\text { pandemic lockdown) }\end{array}$ & 17.0 & YES & -2.47 & $68 \%$ & 4 & 0 \\
$\mathbf{2 0 2 0}$ (November) & 17.6 & YES & -1.58 & $71 \%$ & 4 & 0 \\
\hline
\end{tabular}


an away from every one. This confirms that the IGT status represents a developmental risk factor in pediatric patients with CF. Furthermore, in this case it is conceivable that insulin glargine therapy has contributed preserving him from further clinical worsening, as we had observed in the previous years of COVID-19 pandemic.

According to the latest ISPAD guidelines, insulin therapy is the standard medical treatment in case of CFRD while it could be considered a choice in the case of prediabetes in CF patients showing significant comorbidities, such as difficulty in maintaining weight, poor linear growth, frequent pulmonary exacerbations or worsening of lung function. However, it is still debated whether to initiate insulin in patients with $\mathrm{CF}$ and prediabetes. Few studies on the use of insulin in prediabetic patients have been performed, demonstrating both therapeutic efficacy of insulin treatment [14, 26, 27] and not [9]. However, the latter is a study including both adult and pediatric subjects. Our clinical case underlines the potential role of insulin in the early stages of glucose derangements, even before the diagnosis of CFRD, in a young patient with compromised clinical conditions. CFRD diagnosis was made 4 years after the initiation of insulin therapy when the worsening of glycemic control appeared. This was probably due to the association of several factors: poor therapeutic compliance, pulmonary exacerbation, excessive consumption of high-calorie foods and physical inactivity (due to the COVID-19 pandemic lockdown). It is reasonable to speculate that the early insulin therapy allowed to delay the onset of CFRD and to have a more indolent clinical course of the disease. However, no sufficient evidence is available to demonstrate our hypothesis. Regarding treatment strategies in patients with $\mathrm{CF}$ and prediabetes, further investigations with observational trials are needed to confirm the usefulness of early insulin therapy in the prediabetes stage. Actually, two large studies are in progress to answer this question: "Cystic Fibrosis - Insulin Deficiency, Early Action" (ClinicalTrials.gov Identifier: NCT01100892) and "The Impact of Insulin Therapy on Protein Turnover in PreDiabetic Cystic Fibrosis Patients" (ClinicalTrials.gov Identifier: NCT02496780). The results of these studies will clarify if treatment of prediabetes in patients with $\mathrm{CF}$ is effective to delay the clinical decay of the underlying disease.

During the quarantine, diseases other than COVID-19 remained in the background and patients delayed their regular follow-up visits or did not worry about their symptoms aggravating the onset of many diseases as diabetic ketoacidosis. Blood glucose should be carefully monitored in diabetic patients with COVID19 infection as an increased risk of ketoacidosis has been reported in these patients [28]. Even among patients hospitalized for COVID-19 and without a history of diabetes, an increased mortality rate and prolonged hospitalization were reported in those whose blood glucose levels had increased during the hospitalization period. These data suggest that keeping blood glucose within normal limits can reduce complications and mortality [29]. In pediatric patients, comorbidities such as diabetes, chronic lung disease, tumors, immunodeficiencies, chronic renal failure, and neurological disorders may increase the morbidity-mortality risk related to COVID-19. These patients not only risk a more severe course of COVID19 infection, but also mismanagement of the underlying disease [30]. To reduce this risk, specific follow-up paths should be ensured for these patients even during times of a pandemic. It is essential to avoid the interruption of care for chronic patients even by using alternative pathways such as telemedicine when regular follow-up cannot be guaranteed.

\section{Abbreviations \\ ADA: American Diabetes Association; CF: Cystic Fibrosis; CFRD-FH-: Cystic Fibrosis-Related Diabetes less Fasting Hyperglycemia; CFRD-FH+: Cystic Fibrosis-Related Diabetes plus Fasting Hyperglycemia; CFRD: Cystic Fibrosis- Related Diabetes; CFTR: Cystic Fibrosis Transmembrane Conductance Regulator protein; FEV1: forced expiratory rate in the first second; FPG: Fasting Plasma Glucose; HbA1c: glycosylated haemoglobin; IGT: Impaired Glucose Tolerance; INDET: Indeterminate Glucose Tolerance; ISPAD: International Society for Pediatric and Adolescent Diabetes; NGT: Normal Glucose Tolerance; OGTT: Oral Glucose Tolerance Test; ppFEV1\%: percent predicted forced expiratory rate in the first second; T1DM: Type 1 Diabetes Mellitus; T2DM: Type 2 Diabetes Mellitus}

\section{Acknowledgements}

We thank our patient and his family for their willingness to contribute to the medical and scientific communities by sharing his story.

\section{Authors' contributions}

E.M., A.T., F.M.R. and C.C. wrote the manuscript; F.M.R. and C.C. collected the data; A.S. and A.C. edited the manuscript; V.R. and A.F. reviewed the manuscript. The authors read and approved the final manuscript.

\section{Funding}

No honoraria or grant founding were received by the authors for writing this manuscript.

\section{Availability of data and materials}

All data generated during this study are included in this published article and its supplementary information files.

\section{Declarations}

Ethics approval and consent to participate

Not applicable. This article does not contain any studies with human participants or animals performed by any of the authors.

No potential conflicts of interest relevant to this article were reported.

\section{Consent for publication}

Subjects and their caregivers gave their written informed consent to publish their case.

\section{Competing interests}

The authors declare that they have not competing interests.

\section{Author details}

${ }^{1}$ Regional Center of Pediatric Diabetes, Department of Translational Medical Science, Section of Pediatrics, Federico II University of Naples, Naples, Italy. 
${ }^{2}$ Regional Center of Cystic Fibrosis, Department of Translational Medical Science, Section of Pediatrics, Federico II University of Naples, Naples, Italy.

Received: 30 December 2020 Accepted: 17 May 2021

Published online: 02 June 2021

\section{References}

1. Ratjen F, Doring G. Cystic fibrosis. Lancet. 2003;361(9358):681-9. https://doi. org/10.1016/S0140-6736(03)12567-6.

2. Moran A, Dunitz J, Nathan B, Saeed A, Holme B, Thomas W. Cystic fibrosisrelated diabetes: current trends in prevalence, incidence, and mortality. Diabetes Care. 2009;32(9):1626-31. https://doi.org/10.2337/dc09-0586.

3. Hameed S, Jaffe A, Verge CF. Cystic fibrosis related diabetes (CFRD): the end stage of progressive insulin deficiency. Pediatr Pulmonol. 2011;46(8):747-60. https://doi.org/10.1002/ppul.21495.

4. Franzese A, Mozzillo E, Fattorusso V, Raia V, Valerio G. Screening of glucose metabolism derangements in pediatric cystic fibrosis patients: how, when why. Acta Diabetol. 2015;52(4):633-8. https://doi.org/10.1007/s00592-0150743-y.

5. Mozzillo E, Raia V, Fattorusso V, Falco M, Sepe A, De Gregorio F, et al. Glucose derangements in very young children with cystic fibrosis and pancreatic insufficiency. Diabetes Care. 2012;35(11):e78. https://doi.org/1 $0.2337 / \mathrm{dc} 12-0459$

6. Moran A, Brunzell C, Cohen RC, Katz M, Marshall BC, Onady G, et al. Clinical care guidelines for cystic fibrosis-related diabetes. A position statement of the American Diabetes Association and a clinical practice guideline of the Cystic Fibrosis Foundation, endorsed by the Pediatric Endocrine Society. Diabetes Care. 2010:33:2697-708.

7. Moran A, Pillay K, Becker D, Granados A, Hameed S, Acerini CL. ISPAD clinical practice consensus guidelines 2018 compendium management of cystic fibrosis related diabetes in children and adolescents. Pediatr Diabetes. 2018;19(S 27):64-74

8. Larson Ode K, Frohnert B, Laguna T, Phillips J, Holme B, Regelmann W, et al. Oral glucose tolerance testing in children with cystic fibrosis. Pediatr Diabetes. 2010;11:487-92.

9. Minicucci L, Haupt M, Casciaro R, De Alessandri A, Bagnasco F, Lucidi V, et al. Slow-release insulin in cystic fibrosis patients with glucose intolerance: a randomized clinical trial. Pediatr Diabetes. 2012;13(2):197-202. https://doi. org/10.1111/j.1399-5448.2011.00810.x.

10. Fattorusso V, Casale A, Raia V, Mozzillo E, Franzese A. Long-term follow-up in a girl with cystic fibrosis and diabetes since the first year of life. Diabetes Ther. 2017;8(5):1187-90. https://doi.org/10.1007/s13300-017-0289-9.

11. Milla CE, Warwick WJ, Moran A. Trends in pulmonary function in cystic fibrosis patients correlate with the degree of glucose intolerance at baseline. Am J Respir Crit Care Med. 2001;162:891-5.

12. Nousia-Arvanitakis $S$, Galli-Tsinopoulou A, Karamouzis M. Insulin improves clinical status of patients with cystic fibrosis-related diabetes mellitus. Acta Paediatr. 2001;90(5):515-9. https://doi.org/10.1080/080352501750197647.

13. Rolon MA, Benali K, Munck A, Navarro J, Clement A, Tubiana-Rufi N, et al, CFRD: clinical impact of prediabetes and effects of insulin therapy. Acta Paediatr. 2001;90(8):860-7.

14. Mozzillo E, Franzese A, Valerio G, Sepe A, De Simone I, Mazzarella G, et al. One-year glargine treatment can improve the course of lung disease in children and adolescents with cystic fibrosis and early glucose derangements. Pediatr Diabetes. 2009;10(3):162-7. https://doi.org/10.1111/ j.1399-5448.2008.00451.x.

15. Cheung MS, Bridges NA, Prasad SA, Francis J, Carr SB, Suri R, et al. Growth in children with cystic fibrosis-related diabetes. Pediatr Pulmonol. 2009;44(12): 1223-5. https://doi.org/10.1002/ppul.21127.

16. Ripa P, Robertson I, Cowley D, Harris M, Master IB, Cotterill AM. The relationship between insulin secretion, the insulin-like growth factor axis and growth in children with cystic fibrosis. Clin Endocrinol. 2002:56(3):3839. https://doi.org/10.1046/j.1365-2265.2002.01484.x.

17. Moran A, Doherty L, Wang X, Thomas W. Abnormal glucose metabolism in cystic fibrosis. J Pediatr. 1998;133(1):10-6. https://doi.org/10.1016/S0022-34 76(98)70171-4.

18. Ma R, Benali K, Munck A, et al. Cystic fibrosis related diabetes mellitus: clinical impact of prediabetes and effects of insulin therapy. Acta Paediatr. 2001:90:860-7.
19. Schaedel C, De Monestrol I, Hjelte L, et al. Predictors of deterioration of lung function in cystic fibrosis. Pediatr Pulmonol. 2002;33(6):483-91. https://doi. org/10.1002/ppul.10100.

20. Lavie M, Fisher D, Vilozni D, Forschmidt R, Sarouk I, Kanety H, et al. Glucose intolerance in cystic fibrosis as a determinant of pulmonary function and clinical status. Diabetes Res Clin Pract. 2015;110(3):276-84. https://doi.org/1 0.1016/j.diabres.2015.10.007.

21. Rafii M, Chapman K, Stewart C, Kelly E, Hanna A, Wilson DC, et al. Changes in response to insulin and the effects of varying glucose tolerance on whole-body protein metabolism in patients with cystic fibrosis. Am J Clin Nutr. 2005;81 (2):421-6. https://doi.org/10.1093/ajcn.81.2.421.

22. Franzese A, Spagnuolo MI, Sepe A, Valerio G, Mozzillo E, Raia V. Can glargine reduce the number of lung infections in patients with cystic fibrosis-related diabetes? Diabetes Care. 2005;28(9):2333. https://doi.org/10.2337/diacare.28. 9.2333 .

23. Wainwright CE, Elborn JS, Ramsey BW, Marigowda G, Huang X, Cipolli M, et al. Lumacaftor-Ivacaftor in patients with cystic fibrosis homozygous for Phe508del CFTR. N Engl J Med. 2015;373(3):220-31. https://doi.org/10.1056/ NEJMoa 1409547.

24. Moran A, Pillay K, Becker DJ, Acerini CL. ISPAD clinical practice consensus guidelines 2014 compendium management of cystic fibrosis-related diabetes in children and adolescents. Pediatr Diabetes. 2014;15(S20):65-76. https://doi.org/10.1111/pedi.12178.

25. Bizzarri C, Lucidi V, Ciampalini P, Bella S, Russo B, Cappa M. Clinical effects of early treatment with insulin glargine in patients with cystic fibrosis and impaired glucose tolerance. J Endocrinol Investig. 2006;29(3):RC1-4. https:// doi.org/10.1007/BF03345538.

26. Kolouskova S, Zemkova D, Bartosova J, Skalicka V, Sumnik Z, Vavrova V, et al. Low-dose insulin therapy in patients with cystic fibrosis and early-stage insulinopenia prevents deterioration of lung function: a 30 year prospective study. J Pediatr Endocrinol Metab. 2011;24:499-54.

27. Hameed S, Morton JR, Field PI, Belessis Y, Yoong T, Katz T, et al. Once daily insulin detemir in cystic fibrosis with insulin deficiency. Arch Dis Child. 2012; 97(5):464-7. https://doi.org/10.1136/adc.2010.204636.

28. Ma WX, Ran XW. The management of blood glucose should be emphasized in the treatment of COVID-19. Sichuan Da Xue Xue Bao Yi Xue Ban. 2020; 51(2):146-50. https://doi.org/10.12182/20200360606.

29. Bode B, Garrett V, Messler J, McFarland R, Crowe J, Booth R, et al. Glycemic characteristics and clinical outcomes of COVID 19 patients hospitalized in the United States. J Diabetes Sci Technol. 2020;14(4):813-21. https://doi. org/10.1177/1932296820924469.

30. Evliyaoğlu O. Children with chronic disease and COVID-19. Turk Pediatri Ars. 2020;55(2):93-4. https://doi.org/10.14744/TurkPediatriArs.2020.57805.

\section{Publisher's Note}

Springer Nature remains neutral with regard to jurisdictional claims in published maps and institutional affiliations.

Ready to submit your research? Choose BMC and benefit from:

- fast, convenient online submission

- thorough peer review by experienced researchers in your field

- rapid publication on acceptance

- support for research data, including large and complex data types

- gold Open Access which fosters wider collaboration and increased citations

- maximum visibility for your research: over $100 \mathrm{M}$ website views per year

At BMC, research is always in progress.

Learn more biomedcentral.com/submissions 